\title{
Long-Term Transformation and Fate of Manufactured Ag Nanoparticles in a Simulated Large Scale Freshwater Emergent Wetland
}

Gregory V. Lowry, ${ }^{*},+\perp$ Benjamin P. Espinasse, ${ }^{\dagger, \|}$ Appala Raju Badireddy, ${ }^{\dagger, \|}$ Curtis J. Richardson, ${ }^{\dagger, \S}$ Brian C. Reinsch, ${ }^{\dagger, \perp}$ Lee D. Bryant, ${ }^{\dagger, \|}$ Audrey J. Bone, ${ }^{\dagger, \S}$ Amrika Deonarine, ${ }^{\dagger, \|}$ Soryong Chae, ${ }^{\dagger, \|, \nabla}$ Mathieu Therezien, ${ }^{\dagger, \|}$ Benjamin P. Colman, ${ }^{\dagger, \#}$ Heileen Hsu-Kim, ${ }^{\dagger, \|}$ Emily S. Bernhardt, ${ }^{\dagger}, \#$ Cole W. Matson, ${ }^{\dagger, \ddagger}$ and Mark R. Wiesner ${ }^{\dagger, \|}$

${ }^{\dagger}$ Center for the Environmental Implications of NanoTechnology (CEINT)

"Department of Environmental Sciences, Baylor University, Waco, Texas 76798, United States

${ }^{\S}$ Nicholas School of the Environment, Duke University, Durham, North Carolina 27708, United States

"Civil \& Environmental Engineering, Duke University, Durham, North Carolina 27708, United States

${ }^{\perp}$ Civil \& Environmental Engineering, Carnegie Mellon University, Pittsburgh, Pennsylvania 15213, United States

\#Department of Biology, Duke University, Durham, North Carolina 27708, United States

Supporting Information

ABSTRACT: Transformations and long-term fate of engineered nanomaterials must be measured in realistic complex natural systems to accurately assess the risks that they may pose. Here, we determine the long-term behavior of poly(vinylpyrrolidone)-coated silver nanoparticles (AgNPs) in freshwater mesocosms simulating an emergent wetland environment. AgNPs were either applied to the water column or to the terrestrial soils. The distribution of silver among water, solids, and biota, and $\mathrm{Ag}$ speciation in soils and sediment was determined 18 months after dosing. Most (70 wt \%) of the added $\mathrm{Ag}$ resided in the soils and sediments, and largely remained in the compartment in which they were dosed. However, some movement between soil and sediment was observed. Movement of AgNPs from terrestrial soils to sediments was more facile than from sediments to soils, suggesting that erosion

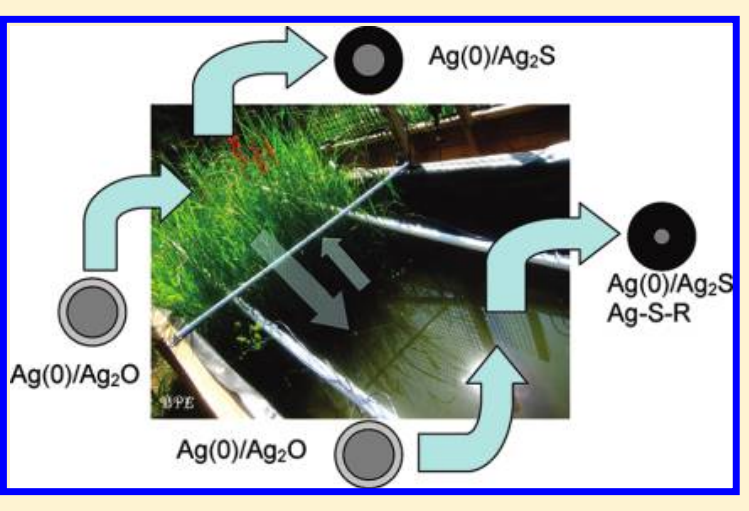
and runoff is a potential pathway for AgNPs to enter waterways. The AgNPs in terrestrial soils were transformed to $\mathrm{Ag}_{2} \mathrm{~S}$ ( $\sim 52 \%)$, whereas AgNPs in the subaquatic sediment were present as $\mathrm{Ag}_{2} \mathrm{~S}(55 \%)$ and Ag-sulfhydryl compounds (27\%). Despite significant sulfidation of the AgNPs, a fraction of the added $\mathrm{Ag}$ resided in the terrestrial plant biomass ( $\sim 3 \mathrm{wt} \%$ for the terrestrially dosed mesocosm), and relatively high body burdens of $\mathrm{Ag}(0.5-3.3 \mu \mathrm{g} \mathrm{Ag} / \mathrm{g}$ wet weight) were found in mosquito fish and chironomids in both mesocosms. Thus, Ag from the NPs remained bioavailable even after partial sulfidation and when water column total $\mathrm{Ag}$ concentrations are low $(<0.002 \mathrm{mg} / \mathrm{L})$.

\section{INTRODUCTION}

The production and use of engineered nanomaterials (ENM) continues to increase, but their fate and impacts in the environment largely remain undetermined. In particular, there is little information on the types of transformations that ENMs will undoubtedly undergo in real, complex environments during long-term aging, and the impact of these transformations on their speciation, distribution in the environment, bioavailability, and toxicity potential. ${ }^{1,2}$ In one study, the fate and bioavailability of $\mathrm{Au}$ NPs were determined in estuarine mesocosms of sufficient size $\left(\mathrm{m}^{3}\right.$ scale) to begin to understand the complex behaviors of nanomaterials in natural systems. ${ }^{3}$ However, this study was conducted for only 12 days, and therefore did not necessarily capture the long-term behavior and effects that may have resulted from more chronic exposures to Au NPs. Here we describe the transformations and distribution of poly(vinylpyrrolidone) (PVP)-coated silver nanoparticles (AgNPs) in a freshwater emergent wetland mesocosm 18 months after their introduction to determine their partitioning behavior, speciation, and the bioavailability of Ag to plants and aquatic species.

Special Issue: Transformations of Nanoparticles in the Environment

Received: December 22, 2011

Revised: March 18, 2012

Accepted: April 1, 2012

Published: April 1, 2012 
There are many factors that may influence the fate, distribution, persistence, and bioavailability of engineered nanomaterials in the environment, including the location where those materials are introduced, and biological ${ }^{4,5}$ and abiotic transformations such as photodegradation, ${ }^{6-10}$ chemical oxidation, ${ }^{11}$ and dissolution. ${ }^{12-15}$ For example, AgNPs may enter aquatic environments through wastewater treatment plant effluent, ${ }^{16}$ or may enter through terrestrial application of biosolids containing AgNPs to agricultural lands. ${ }^{17,18}$ AgNPs entering surface waters will likely be associated with other natural colloids and settle to become sequestered in subaquatic sediment. ${ }^{19}$ AgNPs present in biosolids that are added to terrestrial soils may be mobilized (e.g., runoff) and transported to receiving waters, and ultimately to subaquatic sediments. ${ }^{1,20}$ However, the extent of transport will depend on the types of soil particles that the AgNPs associate with, and the nature of the association. While the transport of natural colloids in the environment has been widely investigated, ${ }^{21}$ the transport of ENMs having synthetic high molecular weight polymeric coatings such as $\mathrm{PVP}^{22-24}$ or gum arabic ${ }^{25}$ is less studied. The presence of polymeric coatings may greatly affect the affinity of attachment to soils, ${ }^{26,27}$ and their subsequent mobility and behavior in the environment. ${ }^{28}$ The fate of AgNPs in realistic complex environments resulting from different routes of entry (water column vs terrestrial application) has not yet been determined.

Transformations such as oxidation, dissolution, or sulfidation will affect the ultimate form of the AgNPs in the environment and may impact bioavailability and toxicity. These transformations will depend on the local environmental conditions. In an oxic environment AgNPs can be oxidized to $\mathrm{Ag}(\mathrm{I})$ species (e.g., $\mathrm{Ag}_{2} \mathrm{O}$ ) that may dissolve to form $\mathrm{Ag}^{+}$ion or complexed $\mathrm{Ag}(\mathrm{I})$ species. ${ }^{29,30}$ In the presence of inorganic or biogenic sulfide, AgNPs may become partially or fully sulfidized to form $\mathrm{Ag}_{2} \mathrm{~S}_{(\mathrm{s})} \cdot{ }^{31,32}$ This sulfidation decreases available $\mathrm{Ag}^{+}$due to the low aqueous solubility of $\mathrm{Ag}_{2} \mathrm{~S}_{(\mathrm{s})}$, and may limit the bioavailability or toxicity of the AgNPs to aquatic organisms. ${ }^{33-35}$ The speciation of AgNPs in terrestrial soils, the water column, and subaquatic sediment in freshwater mesocosms have not been measured under realistic conditions or over time scales that allow for such transformations to occur.

Study Design and Objectives. The mesocosms were designed to allow for the natural processes affecting AgNP behavior and fate in an emergent wetland on a scale large enough to capture the complexity and dynamic nature of real environments. ${ }^{36}$ The mesocosms have a sloped bed that allows for the existence of both an aquatic/subaquatic environment and a terrestrial environment (design shown in detail in the Supporting Information). The terrestrial environment had an unsaturated vadose zone and was largely oxic, whereas the subaquatic sediment was consistently flooded and predominantly anoxic. This mesocosm design mimics an emergent freshwater wetland environment, is open at the top and therefore allows for the volumes of water and the terrestrial/soil compartments to vary with rainfall as may be observed in natural wetland environments, and has been used extensively to study ecosystem responses to perturbations of environmental conditions. $^{37}$

A range of plant species often found in emergent freshwater wetlands were planted in the mesocosms to determine the ability of these types of plants to take up Ag or AgNPs released to the environment. Mosquitofish (Gambusia holbrooki) and other organisms (e.g., insects) were introduced incidentally with the sediments and allowed to colonize the mesocosms naturally prior to and after dosing with AgNPs. At the end of the 18-month study period, the concentration of $\mathrm{Ag}$ in plants, fish, and insects was determined to assess the long-term bioavailability of the transformed Ag NPs to those organisms and relate this bioavailability to the speciation of the AgNPs and free $\mathrm{Ag}^{+}$ion.

To determine if the location of the AgNP addition impacted their behavior and long-term fate, the Ag NPs were added to two identical mesocosms; in the first, AgNPs were added directly to the aquatic compartment with none entering the terrestrial compartment; in the second, the same mass of $\mathrm{Ag}$ NPs was added, but only to the terrestrial compartment, similar to land application of biosolids containing Ag NPs. Enough AgNPs were added to the water column to achieve a total target concentration of $25 \mathrm{mg} / \mathrm{L}$, a value that was selected to ensure that NPs could be tracked through the environment. The 25 $\mathrm{mg} / \mathrm{L}$ value is higher than estimates from exposure models, ${ }^{38}$ although it is lower than many laboratory studies assessing the fate, transport, and effects of AgNPs. ${ }^{24,39-42}$

The primary goals for this study were to determine the distribution and speciation of AgNPs after an extended period of aging in a realistic and complex freshwater environment, and to correlate the properties of the environmental compartments with the observed transformations. Specifically, we determined (1) the movement of $\mathrm{Ag}$ between terrestrial and aquatic compartments and the distribution of $\mathrm{Ag}$ among the various environmental compartments (water, sediment, soil, plants, fish) 18 months after the AgNPs were added and (2) the chemical speciation of the AgNPs in the terrestrial soil and subaquatic sediments where sufficient $\mathrm{Ag}$ had accumulated to allow for speciation to be assessed. The effect of the resulting $\mathrm{Ag}$ speciation on the availability of $\mathrm{Ag}$ to plants and organisms is discussed.

\section{MATERIALS AND METHODS}

Mesocosms. The mesocosms were rectangular shaped boxes constructed of treated wood and were kept outdoors in an open area of the Duke Forest in Durham, NC. Each mesocosm enclosure was $3.66 \mathrm{~m}$ long, $1.22 \mathrm{~m}$ wide and $0.8 \mathrm{~m}$ deep (Supporting Information (SI) Figure S1a). The bed was sloped at $\sim 13$ degrees (SI Figure S1b), and the interior of the mesocosms was lined with a potable water grade quality geotextile $(0.45 \mathrm{~mm}$ reinforced polypropylene, Firestone Specialty Products, U.S.), making the mesocosms watertight. Thus all waters were contained in the system except for losses from evaporation, transpiration, and sample withdrawal. Riparian wetland soil extracted from Sandy Creek (Durham, NC), was air-dried and screened, and added to provide a uniform $22 \mathrm{~cm}$ layer of soil throughout the mesocosm. The soil had an average content of $63 \%$ sand, $10 \%$ clay, and $26 \%$ silt, the loss on ignition is $1.83 \%$. The soils are classified as Cartecay (coarse-loamy, mixed semiactive, nonacid, thermic Aquic Udifluvent)/Chewacla (fine-loamy, mixed, active, thermic Fluvaquentic Endoaquepts) soils. These loam soils are formed on floodplains through alluvial sedimentation and are considered to be hydric soils. ${ }^{43}$ The mesocosms were filled with pristine groundwater extracted from a well at the site in the Duke Forest.

The mesocosms were planted with plugs of Juncus effuses, Carex lurida, Panicum virgatum, and Lobelia cardinalis. (Mellow Marsh Farm, Siler City, NC) on June 23rd 2009, 121 days prior to dosing with Ag NPs. These represent typical wetland species 
found in wetlands in the Southeastern U.S. Eastern mosquitofish (Gambusia holbrooki), a species commonly found in wetlands throughout the southeastern U.S., was incidentally introduced via wetland plant translocations into the mesocosms during the initial planting. Other vertebrates and invertebrates colonized the mesocosms for variable amounts of time over the 18-month study period, including damselflies, dragonflies, and chironomids.

AgNPs. The AgNPs used in this study were purchased from NanoAmor (Houston, TX). They were reported by the manufacturer to be $10 \mathrm{~nm}$ in diameter with a PVP coating $(10000 \mathrm{~g} / \mathrm{mol})$. The physical properties of these particles have been previously described. ${ }^{35,41}$ Briefly, the particles were polydisperse with particle sizes ranging from 30 to $80 \mathrm{~nm}$, and with aggregates of up to $200 \mathrm{~nm}$ in diameter based on TEM and DLS measurements (z-average hydrodynamic diameter). The initial $\mathrm{Ag}(0)$ content as determined by X-ray absorption spectroscopy was $80-85$ wt \% with the balance being an oxidized form of $\mathrm{Ag}$, either $\mathrm{Ag}_{2} \mathrm{O}$ or a mixture of $\mathrm{Ag}_{2} \mathrm{O}$ and $\mathrm{Ag}_{2} \mathrm{~S}$. X-ray diffraction (XRD) confirmed the presence of predominantly crystalline $\mathrm{Ag}(0)$. ICP analysis of the Ag content of a known mass of $\mathrm{Ag} \mathrm{NP}$ powder after acid digestion indicated $70-75 \mathrm{wt} \% \mathrm{Ag}$. The balance of mass is attributed to the PVP coating, which was determined to be $\sim 5$ wt $\%$ using TGA and was reported to be up $\sim 17$ wt $\%$ of these commercially available AgNPs, ${ }^{24}$ and any impurities in the particles. Upon ultrasonication for at least $10 \mathrm{~min}$, the particles formed a dispersion that was stable against sedimentation long enough for dosing the mesocosms as described next.

Mesocosm Dosing. The mesocosms were dosed on October 18, 2009 in either the terrestrial compartment or to the water column. AgNP dispersions were prepared at $700 \mathrm{mg} /$ $\mathrm{L}$ by sonicating $140 \mathrm{mg}$ of the PVP-silver powder in $200 \mathrm{~mL}$ of water at 89-95 W power for $20 \mathrm{~min}$ in an ice bath (Misonix Sonicator 4000, QSonica LLC, Newton, CT). A total of 60 batches were prepared and combined to provide a total of $12 \mathrm{~L}$ of suspension for dosing the mesocosms. Six liters of this suspension were placed in a plastic vessel, pressurized, and then sprayed evenly over either the water column or over the terrestrial environment. A total of $4.2 \mathrm{~g}$ of $\mathrm{AgNPs}(\sim 2.9 \mathrm{~g} \mathrm{Ag})$ was sprayed evenly onto the terrestrial compartment of the first mesocosm over approximately $10 \mathrm{~min}$. Care was taken to minimize the amount of solution that landed on plant leaves and stems. No precipitation occurred during or for at least five days after dosing so the surface of the terrestrial soils dried prior to any subsequent rainfall. However, a limited amount of runoff from the soil to the water column may have occurred during dosing of the terrestrial environment. The same mass of AgNPs was sprayed evenly onto the water surface of the second mesocosm to provide a target initial Ag concentration of 16.6 $\mathrm{mg} / \mathrm{L}(25 \mathrm{mg} / \mathrm{L} \mathrm{AgNPs})$ in the water column.

Determination of $\mathrm{pH}$, Temperature, Total $\mathrm{Ag}$ and Dissolved $\mathrm{Ag}$ in the Water Column. Measurements of $\mathrm{pH}$ and water temperature were made in the center of the water column using a multiparameter probe (YSI556, YSI, Yellow Springs, Ohio) at variable intervals. Total silver was determined from $9.5 \mathrm{~mL}$ water column samples taken at approximately the middle of the mesocosms ( $\sim 10 \mathrm{~cm}$ depth). Water $(1 \mathrm{~mL})$ from inside of dialysis bags ( $3 \mathrm{kDa}$ molecular weight cutoff) floating in the mesocosm water column was defined in our experiments to contain dissolved forms of silver. The dialysis bags were hermetically sealed again after sampling and returned to the mesocosm. At the sample collection site, each sample was immediately acidified with trace metal grade $\mathrm{HNO}_{3}$ (Sigma Aldrich, St. Louis, MO) to a final acid concentration of $5 \%(\mathrm{v} /$ v) and stored at $4{ }^{\circ} \mathrm{C}$ until digestion and analysis as described in the SI.

Ag in Sediment and Terrestrial Soil Core Samples. At the end of the experiment, the water was removed from the mesocosm before taking sediment core samples. A $4.6 \mathrm{~cm}$ inner diameter PVC tube was used to collect core samples in either the sediment or the terrestrial compartment. The cores were sectioned onsite by slicing sections approximately corresponding to different depths $(0-1 \mathrm{~cm}, 1-2 \mathrm{~cm}, 2-4 \mathrm{~cm},>4 \mathrm{~cm})$. Whole slices were then homogenized and weighed. The water content of each sample was determined after drying a portion of the soil at $105{ }^{\circ} \mathrm{C}$ for $48 \mathrm{~h}$. The silver concentration was determined for each subsample after digestion and analysis by graphite furnace AA as described in the SI.

Determination of $\mathrm{Ag}$ Concentration in Plants. The plants were removed manually and washed with groundwater from the same well used to fill the mesocosms to remove adhered soil. The plants were identified (for species), stored individually in paper bags, and dried in a forced air oven at 70 ${ }^{\circ} \mathrm{C}$ for $48 \mathrm{~h}$. All plants were then weighed within $3 \mathrm{~h}$ after drying. Roots were differentiated from the shoots and leaves, for every species and subspecies. Subsamples for silver analysis of every root species were rewashed again with DI water to ensure that no soil residue was present on the root samples and then were dried again. The silver concentration was determined for each subsample by graphite furnace AA after digestion and analysis as described in the SI.

Determination of $\mathrm{Ag}$ Concentration in Fish and Insects. Mosquitofish, chironomids, and dragonfly larvae were collected by hand-net and were immediately flash frozen. Fish were processed individually, with eight replicates per mesocosm. Dragonfly larvae were pooled into groups of two or three, with nine pooled replicates for the mesocosm with AgNPs added to the water column, and three for the mesocosm with Ag NPs added to the terrestrial soil. Chironomids were run as three pooled replicates for the aquatic mesocosm and there were only sufficient numbers for a single replicate for the terrestrial mesocosm. The total silver concentration in fish and insects was determined for each subsample after digestion and analysis by ICP-MS as described in the SI.

To investigate potential maternal transfer of $\mathrm{Ag}$ from mosquitofish mothers into their eggs and/or developing embryos, three gravid females were collected from each mesocosm. As mosquitofish are ovoviviparous, their eggs are internally fertilized and develop internally prior to hatching. Following euthanasia with MS-222 (Sigma Aldrich, St. Louis, $\mathrm{MO}$ ), late-term developing embryos were removed from gravid females. Mothers were analyzed individually and embryos were pooled (by mother) for analysis. Samples were flash frozen and subsequently processed for Ag body burdens as described above.

Redox Conditions at the Sediment-Water Interface. A $4 \mathrm{~cm}$ diameter undisturbed subaquatic sediment core was obtained from each of the two mesocosm prototypes on May 19, 2010 ( $\sim 6$ months after dosing). Vertical concentrationdepth profiles of dissolved manganese $\left(\mathrm{Mn}^{2+}\right)$, iron $\left(\mathrm{Fe}^{2+}\right)$, and oxygen $\left(\mathrm{O}_{2}\right)$ were measured at $1 \mathrm{~mm}$ scale resolution across the sediment-water interface (SWI) of the cores using a solid-state mercury-gold amalgam voltammetric microelectrode as described previously. ${ }^{44}$ Details of the electrode construction and voltammetric scan parameters are provided in the SI. After 
voltammetric electrode profiling of sediment cores, the upper $\sim 2-3 \mathrm{~cm}$ of sediment from the cores was transferred into sterile glass containers. The samples were digested and analyzed for selected metals ( $\mathrm{Ag}, \mathrm{Cu}, \mathrm{Co}, \mathrm{Zn}, \mathrm{Ni}, \mathrm{Pb}$, and $\mathrm{Cd}$ ) by ICPMS as described in the SI.

Acid Volatile Sulfide (AVS) and Selected Heavy Metals. Subaquatic sediments for acid volatile sulfide (AVS) determination were collected directly from each of the mesocosms in glass jars. These samples were sealed and frozen until analysis. AVS was quantified in these samples by acid leaching (with dilute $\mathrm{HCl}$ ), volatilization of $\mathrm{H}_{2} \mathrm{~S}$ and subsequent trapping in $\mathrm{NaOH}$, followed by colorimetric detection of sulfide by the Cline method. ${ }^{45,46}$ Water content of the sediments was determined from the change in sample mass after heating at $102{ }^{\circ} \mathrm{C}$ for at least $12 \mathrm{~h}$. All concentrations were normalized to dry mass of sediment.

Calculation of Total Ag Mass in Environmental Compartments and the Ag Mass Balance. The concentration of total $\mathrm{Ag}$ was determined in the environmental compartments including the water column, the subaquatic sediments, the terrestrial soils, and plant biomass 18 months after introduction of the AgNPs. To best estimate the mass of Ag residing in the sediment and soil, a grid pattern was used to collect samples (SI Figure S2). The depth of penetration of Ag into the sediment is an important factor affecting the mass balance of $\mathrm{Ag}$ measured in the system since the measured concentration is multiplied by the sediment volume to determine the total mass of Ag. To get as accurate as possible an estimate of total $\mathrm{Ag}$ in the sediment and terrestrial compartments, cores were segmented by depth: $0-1 \mathrm{~cm}, 1-$ $2 \mathrm{~cm}, 2-4 \mathrm{~cm},>4 \mathrm{~cm}$. This provided a total of 72 samples $(18$ locations $\times 4$ depths, see SI Figure S2). The sediments and soils were heterogeneous so instead of assuming a constant bulk density of the soil, the dry weight of each layer in each core was measured. The total mass of $\mathrm{Ag}$ in each of the 18 "blocks" was then calculated based on the measured $\mathrm{Ag}$ concentration in each slice ( $\mathrm{mg} / \mathrm{kg}$ dry weight) and the total dry weight of the soil determined of that slice in the core. It was assumed that the dry weight measured in the slice of the core represented that layer for the "block" of the mesocosm (SI Figure S2) from which it was sampled.

While the total plant biomass was measured, the mass of the individual components (leaf, root, stem) was unfortunately not measured and therefore the mass of Ag in plants could not be calculated directly. Juncus sp. was the major plant species and the majority of the Ag mass was associated with the plant roots. Therefore, the total mass of $\mathrm{Ag}$ in the plant biomass was estimated based on concentration of $\mathrm{Ag}$ measured in the roots, and the average Ag concentration in the shoot (average stem and leaf), and using a plant root to shoot mass ratio of 0.25 measured for Juncus in the mesocosms.

Ag Speciation in Mesocosms Soils. The speciation of Ag present in the mesocosms was determined using X-ray Absorption Spectroscopy (XAS) and linear combination fitting as previously described. ${ }^{31,41}$ Samples from both the terrestrial soils and surficial sediment (top $\sim 1 \mathrm{~cm}$ ) were collected at various locations within the mesocosms in May, $2011(\sim 18$ months after dosing). Surficial samples of the subaquatic sediment, including solids and water, were collected with plastic pipettes and placed into centrifuge tubes. The resulting solids and water mixture was centrifuged and the pellet was saved for $\mathrm{X}$-ray analysis. The terrestrial soil samples were scraped from the soil and placed into centrifuge tubes, with care taken to minimize the amount of plant matter and rocks within the vial. The samples were loaded as moist solids into Teflon sample holders with Kapton tape windows for synchrotron X-ray absorption spectroscopy (XAS) analysis. The concentration of total $\mathrm{Ag}$ in the subaquatic sediment and terrestrial soil was approximately $30 \mathrm{mg} / \mathrm{kg}$ and $70 \mathrm{mg} / \mathrm{kg}$, respectively, as determined from ICP-MS on samples previously collected in those mesocosms.

Ag K-edge X-ray absorption spectroscopy (XAS), including the extended X-ray absorption fine structure (EXAFS), out to an energy equal to $K=9$, was performed at the Stanford Synchrotron Radiation Laboratory (SSRL) at BL4-3. Data collection and analysis procedures, including data refinement and background subtraction, were similar to those previously described. $^{31,41,42}$ Linear combination fitting was performed using a model compound library of the chi(k) data out to $k=9$ as previously described. ${ }^{47,48}$ One additional model compound (Ag-cysteine) was used here and not reported previously. This consisted of a $10 \mathrm{mM}$ L-cysteine $+10 \mathrm{mM} \mathrm{Ag(I)}\left(\right.$ as $\left.\mathrm{AgNO}_{3}\right)$, aged for $1 \mathrm{~h}$ at a $\mathrm{pH} 7.47$.

\section{RESULTS}

Transient Behavior after Dosing. AgNPs rapidly sedimented from the water column over the first 8 days as evidenced by the rapid drop off of total Ag concentration in the water column (SI Figure S3a). After the particles had settled, the total Ag concentration in the water column decreased to sub part-per-million concentrations for the duration of the study. The terrestrial application of AgNPs resulted in less Ag in the water column (SI Figure S3a), but a similar rate of decrease in total Ag in the water column was observed for both dosing methods. In both applications, the Ag concentration in the water column was higher than in the water column of a similar undosed control mesocosm which was not detected in analysis. The addition of AgNPs did not greatly affect the $\mathrm{pH}$ of the mesocosm water which remained near neutral during the study (SI Figure S3b).

Sediment Redox Conditions. Sediment depth profiles of dissolved $\mathrm{O}_{2}, \mathrm{Fe}^{2+}$, and $\mathrm{Mn}^{2+}$ indicated a redox gradient in the top $20 \mathrm{~mm}$ of the sediments (Figure 1). While an oxic sediment zone was present in the upper 3-5 $\mathrm{mm}$ of sediment of both mesocosms, the depths of $\mathrm{O}_{2}$ penetration and appearance of reduced metals differed considerably (Figure 1). In both mesocosms the dissolved oxygen was depleted within the first 5 $\mathrm{mm}$ of the sediment, indicating anoxic conditions had prevailed below this layer within the sediment. In the mesocosm where AgNPs were added to the water column and therefore sediment concentrations of $\mathrm{Ag}$ were higher, an increase in both $\mathrm{Fe}$ (II) and $\mathrm{Mn}$ (II) was observed at a shallower depth than for the mesocosms where the AgNPs were added to the terrestrial environment. However, it cannot be ruled out that the variation in redox conditions between the two mesocosms was not simply a result of heterogeneity between the samples. Regardless, these measurements indicated reducing conditions in the near surface sediment in both mesocosms. Similar measurements were not made in the terrestrial soils because the voltammetric electrodes are difficult to employ in unsaturated soils.

Measurement of AVS in the same sediments confirmed reducing conditions and the presence of available sulfide, with AVS ranging from 50 to $110 \mu \mathrm{mol} / \mathrm{kg}$ sediment (dry wt.). The lower end of the AVS range occurred in the mesocosm with terrestrial addition of AgNPs, while the upper end of the range 

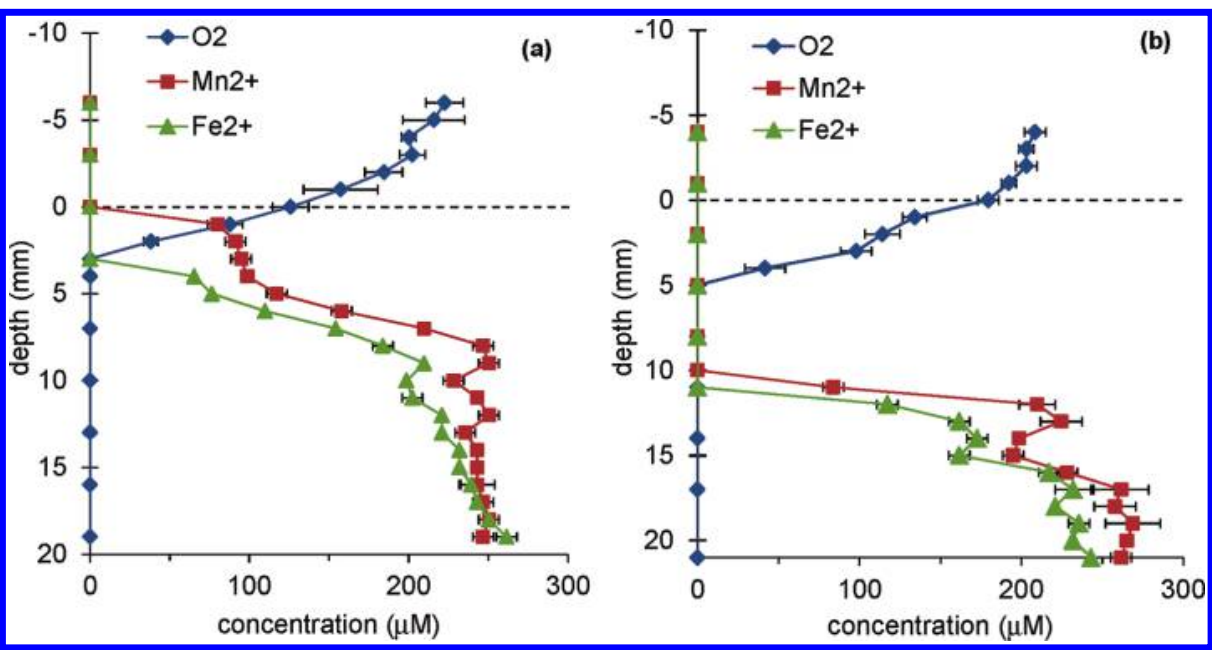

Figure 1. Profiles of dissolved $\mathrm{O}_{2}, \mathrm{Mn}^{2+}$, and $\mathrm{Fe}^{2+}$ in sediment cores taken from mesocosms where AgNPs were added to (a) the water column, and (b) the terrestrial soil. Cores were collected and concentration profiles were quantified 215 days after dosing with AgNPs. Data points correspond to the average ( \pm 1 standard deviation) of 3 measurements repeated at each depth.

occurred in the mesocosms with the water column addition of AgNPs. This molar concentration of AVS is similar to the amount of AgNPs measured in the sediment and terrestrial compartments of the mesocosms $(\sim 100 \mu \mathrm{mol} \mathrm{Ag} / \mathrm{kg}$ dry weight) as discussed below. Monovalent silver has a strong affinity to bind to sulfide, particularly when compared to other metals such as $\mathrm{Fe}^{2+}$. While the AVS measurement methodology is not expected to fully extract (nonacid soluble) $\mathrm{Ag}_{2} \mathrm{~S}$, ${ }^{49}$ the presence of other forms of sulfide (such as $\mathrm{FeS}$ ) suggests that sulfide is available to bind or sorb $\operatorname{Ag}(+\mathrm{I})$ in the sediments.

Long-Term Partitioning Behavior of $\mathrm{Ag}$ in the Mesocosms. Determining the distribution of $\mathrm{Ag}$ among the various environmental compartments is an important factor in assessing the exposure potential and routes of exposure for AgNPs. The concentration of total Ag remaining in the water column at the time of sampling $(\sim 18$ months $)$ was below the detection limit $(<2 \mu \mathrm{g} / \mathrm{L})$. It should be noted that biofilms were not apparent on the mesocosm liner surfaces and attempts to collect biofilm for Ag analysis were unsuccessful. Thus, the majority of the $\mathrm{Ag}$ resided in the other compartments; mainly the sediment and terrestrial soils (Table 1 ). The majority of the Ag remained in the location where it was dosed (Figure 2a,b), however some transfer between the terrestrial and aquatic compartments occurred over the 18 month period. In general, Ag was primarily present in the upper layer of surficial sediment $(0-1 \mathrm{~cm})$ and terrestrial soils after 18 months. Application to the water column resulted in a greater depth of mixing, especially in the far end of the mesocosm away from the slope where sediment accumulated.

Most of the recovered $\mathrm{Ag}$ mass remained in the terrestrial soils or sediment, but an appreciable mass of $\mathrm{Ag}$ was found in the plant biomass at the end of the study. Tissue concentrations in plants recovered from dosed mesocosms were variable over the range of plant species present (SI Table S2) in the mesocosms, but well above background concentrations of 0.04 $\mathrm{mg} / \mathrm{kg}$ measured in undosed mesocosms. Generally the root concentrations were higher than the shoot concentrations. The total mass of Ag in plants accounted for approximately $0.2 \mathrm{wt} \%$ $(6 \mathrm{mg})$ and $3 \mathrm{wt} \%(90 \mathrm{mg})$ of the total $\mathrm{Ag}$ introduced into the mesocosm for the aquatic and terrestrial dosed mesocosm, respectively.
Table 1. Estimated Distribution of Mass of Ag Recovered in Mesocosms Dosed in either the Terrestrial Compartment or the Water Column ${ }^{a}$

\begin{tabular}{lcc} 
& \multicolumn{2}{c}{ location of dose } \\
\cline { 2 - 3 } \multicolumn{1}{c}{ compartment } & terrestrial soil & water column \\
water column & $<0.03 \%$ & $<0.05 \%$ \\
terrestrial soil & $58 \%$ & $7 \%$ \\
subaquatic sediment & $11 \%$ & $60 \%$ \\
plants & $3 \%$ & $0.2 \%$ \\
total recovered & $\mathbf{7 6 \%}$ & $\mathbf{6 8 \%}$
\end{tabular}

${ }^{a}$ Note that the total mass of $\mathrm{Ag}$ added to each mesocosm was approximately $2.9 \mathrm{~g}$. The upper limit of mass in the water column is based in the MDL of $2 \mu \mathrm{g} / \mathrm{L}$ and a total water volume of $500 \mathrm{~L}$ (terrestrial dosed) and $726 \mathrm{~L}$ (water column dosed) at the time of sampling. The principle error associated with estimating silver mass in plant biomass comes from using the average root to shoot ratio of 0.25 measured for Juncus sp. This results in errors of approximately $30 \%$ of the estimates mass. Principle errors in estimating the mass of Ag in soil and sediment come from variance in the measured $\mathrm{Ag}$ concentration (Figure 2), and from heterogeneity in soil properties within each grid block (SI Figure S2). The total plant mass collected was 16.6 and 10.5 $\mathrm{kg}$ in the terrestrial dosed and water column dosed mesocosms, respectively. The total soil masses and measured $\mathrm{Ag}$ concentration in each sample and at each depth are provided in SI Table S3.

Even though fish and insects were not a major sink for $\mathrm{Ag}$ in the system, mosquitofish, dragonfly larvae, and chironomids living in both mesocosms showed relatively high levels of $\mathrm{Ag}$ uptake. Average body burden of $\mathrm{Ag}$ ranged from 0.5 in mosquitofish to as high as $3.3 \mu \mathrm{g} \mathrm{Ag} / \mathrm{g}$ wet weight in chironomids (Figure 3a). These body burdens were orders of magnitude higher than those observed in similar mesocosms that had not been dosed with AgNPs (e.g., $22 \mathrm{ng} \mathrm{Ag} / \mathrm{g}$ wet weight for mosquitofish). There was no statistically significant difference in Ag body burdens between mesocosms for mosquitofish or chironomids. Dragonfly larvae from the aquatic-dosed mesocosm had more than double the amount of $\mathrm{Ag}$ than those from the terrestrial-dosed mesocosm ( $p=$ 0.0001). Mosquitofish mothers and developing embryos were also sampled to investigate maternal transfer of Ag. Female mosquitofish transferred $\mathrm{Ag}$ to developing embryos during development, with body burdens in embryos an order of 

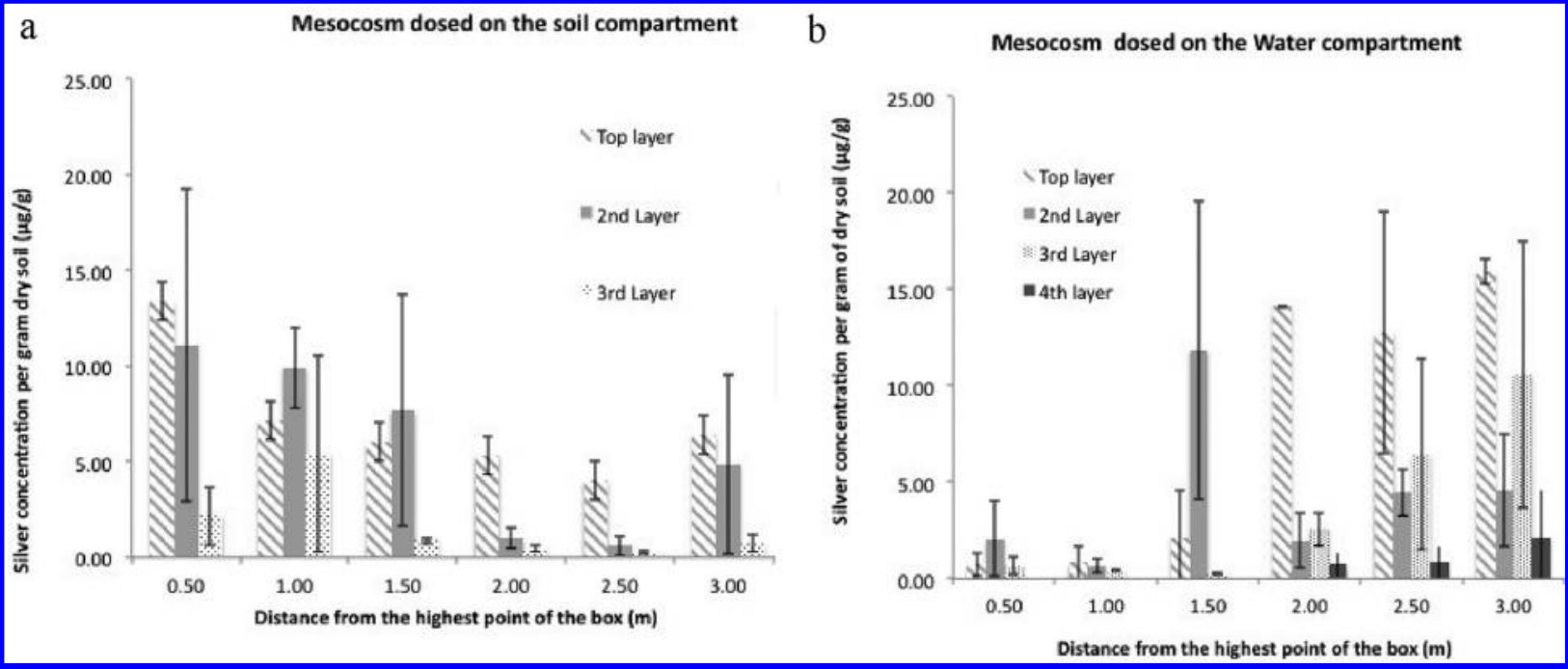

Figure 2. Distribution of total Ag measured in sediments or soil of a) the mesocosm with Ag NPs dosed in the terrestrial compartment, and b) the mesocosm with Ag NPs dosed in the water column. Values reported for each distance are the averge of the three measurements taken at that distance from the edge of the mesocosm; for example, the average Ag concentration measured at points $(0.5 \mathrm{a}, \mathrm{b}$, and c in SI Figure S2) are named 0.5. Error bars are the standard error of the three measurements. Background Ag concentrations in soil from undosed mesocosms was below the detection limit of $\sim 0.5 \mu \mathrm{g} / \mathrm{g}$.

magnitude higher than control fish, and almost $50 \%$ of that found in adult exposed fish (Figure 3b).

Speciation of $\mathrm{Ag}$ in Sediment and Terrestrial Soils. Eighteen months after dosing, the AgNPs added to the system were partially oxidized and sulfidized, with the degree of sulfidation dependent on the compartment where they resided. AgNPs recovered from terrestrial soils contained $\mathrm{Ag}_{2} \mathrm{~S}$ $($ acanthite $)=52 \% \pm 1 \%$, and $\mathrm{Ag} 0=47 \% \pm 1 \%$ (Figure $4 \mathrm{a})$. The R-factor for the LCF analysis was equal to 0.0398, indicating a good fit of the data. AgNPs recovered from the subaquatic sediment were more oxidized than those added to the terrestrial compartment; $\sim 18 \%$ of the original $\mathrm{Ag}^{0}$ character remained after aging. Oxidized silver species were more variable than for the terrestrial case and included a match to reference spectra for $\mathrm{Ag}_{2} \mathrm{~S}=55 \% \pm 6 \%$ and Ag-Cysteine $=27 \% \pm 6 \%$ (Figure 4b). The R-factor for the model fit was equal to 0.229 . While it is unlikely that Ag existed solely as Ag-cysteine in the samples, the need to incorporate the reference spectra for this compound suggests that a proportion of the silver was coordinated to sulfhydryl-containing organic ligands. The concentration of $\mathrm{Ag}$ in sediments collected from the mesocosm with AgNPs added to the terrestrial compartment was too low to allow for XAS analysis. Similarly, there was an insufficient concentration of AgNPs in terrestrial soils for the mesocosm dosed to the water column for XAS analysis.

\section{DISCUSSION}

Transient Behavior of Ag in Water Column and Effect of Sediment Redox Conditions. The AgNPs applied to the water column rapidly settled into the aquatic sediments. The suspended particles accounted for most of the $\mathrm{Ag}$ measured in the water column during the first 8 days as dissolved $\mathrm{Ag}$ ions in solution were below detection limits using ICP-MS $(2 \mu \mathrm{g} / \mathrm{L})$. According to TEM images of particles collected from the water column, the particles existed primarily as aggregates in the water column (SI Figure S4). The 8-day settling time was longer than expected based on homoaggregation studies with these AgNPs at the same particle concentration. The resistance to aggregation and settling may be a result of the very high organic matter concentrations $(\sim 50 \mathrm{mg} / \mathrm{L})$ measured in the water column at the time of dosing (SI Figure S5). Dissolved organic matter can dramatically improve resistance to aggregation. $^{50-52}$ However, the sedimentation of particles from the water column to the subaquatic sediment occurred relatively rapidly compared to the total duration of the study. The measurements of redox active species (i.e., dissolved $\mathrm{O}_{2}$, $\mathrm{Fe}^{2+}$, and $\mathrm{Mn}^{2+}$ ) indicated large gradients in redox potential at the sediment-water interface. While such a gradient is typical for a sediment water interface, ${ }^{53}$ the lower potential at the sediment-water interface for the water column dosed mesocosm which had much higher AgNP concentrations compared to the terrestrial dosed mesocoms suggests that the $\mathrm{Ag}(0)$ in the AgNPs acted as a chemical reductant (i.e., redox reactions stemming from the oxidation of $\operatorname{Ag}(0)$ to $\operatorname{Ag}(+\mathrm{I}))$ in addition to other available reductants (e.g., organic carbon). The AgNPs may have also acted as an indirect reductant by inducing changes to the water quality that facilitated rapid consumption of dissolved $\mathrm{O}_{2}$ (i.e., release of labile organic carbon from plants and microbes exposed to silver).

Partitioning Behavior and Mobility of AgNPs Between Environmental Compartments. The partitioning behavior of AgNPs added to either the terrestrial soil (e.g., in biosolids) or to the water column (which are then rapidly deposited to the sediment) indicate that they can move between compartments. This suggests that runoff during rain events or flooding events may mobilize soil particles and attached nanoparticles from terrestrial soils, providing a potential pathway for nanoparticles to enter surface waters directly or bound to soil particles. Transport from the subaquatic sediment to the soils appears to be from movement of the AgNPs themselves during flooding events since the concentration of dissolved $\mathrm{Ag}$ in the water column was very low compared to the mass of silver in the subaquatic sediment. Since most of the transport from the sediment to the terrestrial environment occurred in the region closest to the water line (Figure 2), it is possible that the AgNPs transferred along with movement of algal/microbial/ mineral floc at the sediment-water interface that is mobilized as 


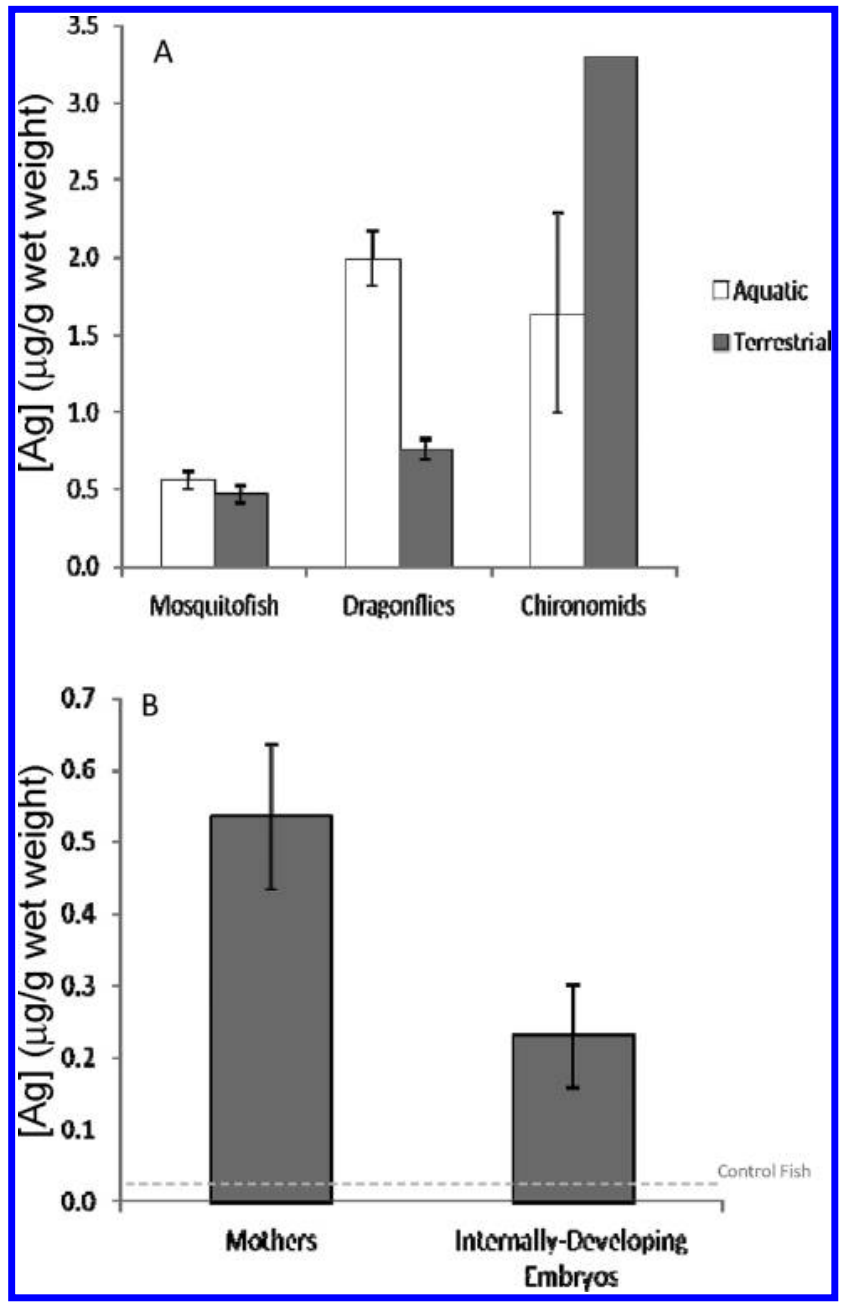

Figure 3. Tissue concentrations of $\mathrm{Ag}$ collected from various organisms from both the aquatic- and terrestrially dosed mesocosms. (a) Total $\mathrm{Ag}$ body burden data for organisms inhabiting the two mesocosms. Mosquitofish, dragonfly larvae, and chironomids all had significant accumulation of Ag. The only significant difference between concentrations for the two mesocosms was for dragonfly larvae, which was higher in the aquatic-dosed mesocosm $(p=0.0001)$. Chironomids had the opposite pattern, with a higher concentration in the group from the terrestrially dosed mesocosm. However, there was only a single pooled sample analyzed for chironomids from the terrestrially dosed mesocosm. (b) Maternal transfer of $\mathrm{Ag}$ was confirmed for mosquitofish. Female mosquitofish were shown to load a significant amount of $\mathrm{Ag}$ into developing embryos, with estimates an order of magnitude higher than control fish from similar mesocosms. Data from both mesocosms were combined for maternal transfer analysis Error bars represent SE.

the water level increases. Most of the Ag was found in this top layer of sediment.

The majority of the Ag added to the system remained in the soil or terrestrial compartments, but interestingly, $3 \mathrm{wt} \%$ versus 0.2 wt \% of the mass of $\mathrm{Ag}$ added was found in the plant biomass 18 months after dosing to the terrestrial compartment or water column, respectively. The 10-fold higher amount of silver in plants for the terrestrial dosed compared to the water column dose cannot be accounted for solely in the greater total biomass recovered in that mesocosm $(16.6 \mathrm{~kg})$ compared to the water column dosed mesocosm $(10.5 \mathrm{~kg})$. It indicates that for the dosing method used here, AgNPs in the terrestrial environment were more available to plants than silver that had

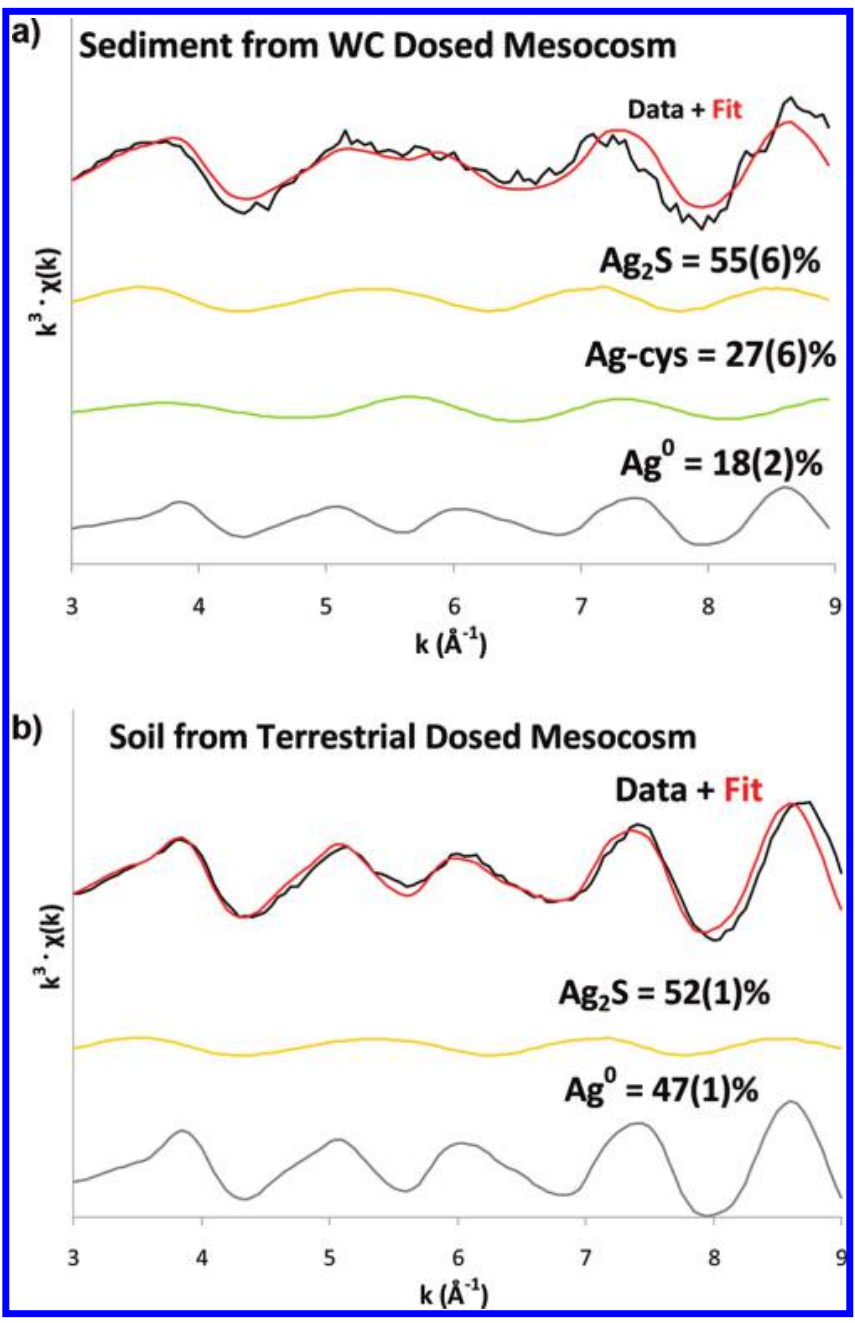

Figure 4. Speciation of AgNPs aged in the mesocosms for 18 months determined from EXAFS analysis and linear combination fitting with spectra from reference materials $\left(\mathrm{Ag}_{2} \mathrm{~S}, \mathrm{Ag}\right.$ (cysteine) complexes, and $\mathrm{Ag}^{0}$ foil. (a) Determined in terrestrial soils for AgNPs dosed onto the terrestrial soils. (b) For AgNPs in subaqueous surficial sediment taken from the mesocosm that had been dosed with AgNPs in the water column.

settled into the subaquatic sediment. This observation is consistent with the fact that water column concentrations of $\mathrm{Ag}$ were below detection during the most of the study, and thus uptake by plants growing in standing water was limited. Similarly to plants, relatively high body burdens of $\mathrm{Ag}$ were observed in fish and insects (Figure 3a), and transfer of $\mathrm{Ag}$ from mosquitofish to embryos was observed (Figure $3 b$ ). The accumulation of $\mathrm{Ag}$ in plants and these animals, even after the first senescence, suggests that a portion of the $\mathrm{Ag}$ remains bioavailable after settling into aquatic sediments and after partial sulfidation to $\mathrm{Ag}_{2} \mathrm{~S}$ and other Ag- sulfhydryl and inorganic $\mathrm{Ag}$ phases as described next.

Speciation and Bioavailability of AgNPs in Mesocosms. The XAS data indicated that a large fraction of the $\operatorname{Ag}(0)$ originating from the NPs was oxidized to $\operatorname{Ag}(\mathrm{I})$ and subsequently sulfidized to form acanthite $\left(\mathrm{Ag}_{2} \mathrm{~S}\right)$ phases in the terrestrial applied mesocosms. $\mathrm{Ag}_{2} \mathrm{~S}$ as well as Ag-sulhydryl species (e.g., Ag complexed with reduced $S$ in organic matter) were present in sediments taken from mesocosms where AgNPs had been applied to the water column. This result is consistent with the fact that $\mathrm{Ag}_{2} \mathrm{~S}$ and Ag-sulfhydryl compounds 
are known to be the most thermodynamically likely, low temperature, geochemical phases for monovalent Ag. ${ }^{54}$ Particles in the aquatic sediments were sulfidized to a greater degree than those present in the terrestrial compartment. The lower extent of oxidation and sulfidation of AgNPs aged in the terrestrial environment was consistent with the drier and more oxic conditions in this compartment compared to sediments which were always anoxic. There was also less AVS in the terrestrial environment available to the particles. The level of sulfidation found in AgNPs in terrestrial soils was greater than might be expected for purely oxic soils, but likely occurred during periods of prolonged rainfall when the terrestrial soils were flooded for extended periods, allowing the soils to go anoxic or anaerobic through microbial action, resulting in partial sulfidation of the AgNPs. These results suggest that AgNPs that are continuously exposed to anoxic conditions and submerged in sediment will be more quickly oxidized and sulfidized than those residing in relatively dryer and oxic terrestrial environments. Differences in the degree of sulfidation of the AgNPs can impact their bioavailability and toxicity. ${ }^{35}$

The transformation of $\mathrm{AgNPs}$ to $\mathrm{Ag}_{2} \mathrm{~S}$ remained incomplete even after 18 months. Thus, sulfidation occurred much slower than had been observed in laboratory studies using $\mathrm{Na}_{2} \mathrm{~S}$ as the source of sulfide. ${ }^{31,32}$ The slower sulfidation of the AgNPs in the sediments compared to laboratory sulfidation may be a result of the relatively low AVS/Ag molar ratio (0.5-1 in the terrestrial soil and sediment) and the presence of other metals (e.g., Fe) that would compete for the sulfide. The slower sulfidation could also be due to a limited amount of oxidant (e.g., dissolved oxygen) that would be required to oxidize the AgNPs during the sulfidation process. ${ }^{29}$

Despite partial transformation of the AgNPs to $\mathrm{Ag}_{2} \mathrm{~S}$ and to Ag-sulfhydryl species, Ag remained bioavailable to plants and to biota that grew after the first senescence (approximately 6 months after dosing). The pathways of uptake were not studied here, but potentially this is a result of the partial sulfidation of the AgNPs and the mechanism of sulfidation that occurs. Given the low levels of AVS in the sediment, sulfidation may be occurring as a two step process whereby the particles oxidize and dissolve to release free $\mathrm{Ag}^{+}$ion which is then transformed to $\mathrm{Ag}_{2} \mathrm{~S}$ and the Ag-sulfhydryl phases observed. ${ }^{32}$ Silver thiosulfate complexes may also form, but a model compound for this complex was not included in the EXAFS study. Fortin and Campbell $(2001)^{55}$ found that silver uptake in aquatic systems was greater in the presence of thiosulfate than based on the free $\mathrm{Ag}^{+}$water concentrations, and importantly, their studies suggest the presence of an inorganic anion transport system where a $\mathrm{Ag}$-thiosulfate complex could give rise to increased uptake in higher organisms, including fish. This suggests that partial sulfidation, which should dramatically decrease $\mathrm{Ag}^{+}$ion release, does not completely prevent uptake of $\mathrm{Ag}$ by organisms. It has been reported that $\mathrm{Ag}^{+}$added to sediments will not be bioavailable (or toxic) for Ag/AVS ratios of less that 2, that is, greater than a stoichiometric amount of sulfur to form $\mathrm{Ag}_{2} \mathrm{~S} .{ }^{56}$ Here, AgNPs appeared to remain bioavailable despite having a Ag/AVS ratio of less than 2 . This is likely a result of the particulate nature of the added Ag and the partial sulfidation.

Here we report, for the first time, the long-term environmental fate of a commercially available AgNP applied to a largescale mesocosm simulating a freshwater emergent wetland. Extensive, but incomplete sulfidation of the AgNPs occurred after 18 months, which based on laboratory studies would be expected to decrease Ag bioavailability. ${ }^{31,35}$ Even though the time at which $\mathrm{Ag}$ uptake occurred was unknown, $\mathrm{Ag}$ remained bioavailable to plants and to other aquatic and sedimentdwelling biota that grew after the first senescence, so long-term availability of $\mathrm{Ag}$ is likely. Additional work is needed to determine how long the $\mathrm{Ag}$ remains bioavailable, and to determine the bioavailable form of $\mathrm{Ag}$ in the mesocosms (e.g., $\mathrm{Ag}$ ion vs Ag-sulfhydryl compounds vs $\mathrm{Ag}_{2} \mathrm{~S}$ NPs). These questions are currently being addressed in smaller scale wellcontrolled studies to support ongoing long-term study with this mesocosm facility.

\section{ASSOCIATED CONTENT}

\section{S Supporting Information}

Supporting Information includes schematic drawings of the mesocosms, the sediment and soil sampling grid, water column total silver concentration, $\mathrm{pH}$, temperature, and $\mathrm{DOC}$ vs time in the mesocosms, TEM image and EDS spectrum of an aggregate of AgNPs recovered from the water column, method details of the sediment profiling with microelectrodes, metals analysis, and measured $\mathrm{Ag}$ concentrations in plant tissues, measured $\mathrm{Ag}$ concentrations and soil and sediment masses used to calculate the distribution of $\mathrm{Ag}$ in the mesocosm. This material is available free of charge via the Internet at http:// pubs.acs.org.

\section{AUTHOR INFORMATION}

\section{Corresponding Author}

*Phone: 412-268-2948; fax: 412-268-7813; e-mail: glowry@ cmu.edu.

\section{Present Address}

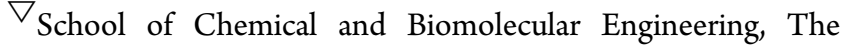
University of Sydney, NSW 2006, Australia.

\section{Notes}

The authors declare no competing financial interest.

\section{ACKNOWLEDGMENTS}

We thank the office of the Duke Forest for their assistance in development of the site and Dr. Curtis Richardson for the innovative mesocosm design that allows simultaneous study of both a terrestrial and aquatic environment. This material is based upon work supported by the National Science Foundation (NSF) and the Environmental Protection Agency (EPA) under NSF Cooperative Agreement EF-0830093, Center for the Environmental Implications of NanoTechnology (CEINT), and EPA's Science to Achieve Results (STAR) program (RD834574). Any opinions, findings, conclusions or recommendations expressed in this material are those of the authors and do not necessarily reflect the views of the NSF or the EPA. This work has not been subjected to EPA review and no official endorsement should be inferred. We thank Matthew Wiesner for his contributions to mesocosm construction and monitoring. Dr. Mengchi Ho and Wes Willis were instrumental in plant collections and analytical Ag analysis, respectively.

\section{REFERENCES}

(1) Klaine, S. J.; Alvarez, P. J. J.; Batley, G. E.; Fernandes, T. F.; Handy, R. D.; Lyon, D. Y.; Mahendra, S.; McLaughlin, M. J.; Lead, J. R. Nanomaterials in the environment: Behavior, fate, bioavailability, and effects. Environ. Toxicol. Chem. 2008, 27, 1825-1851.

(2) Wiesner, M. R.; Lowry, G. V.; Casman, E.; Bertsch, P. M.; Matson, C. W.; Di Giulio, R. T.; Liu, J.; Hochella, M. F. Meditations 
on the ubiquity and mutability of nano-sized materials in the environment. ACS Nano 2011, 5, 8466-8470.

(3) Ferry, J. L.; Craig, P.; Hexel, C.; Sisco, P.; Frey, R.; Pennington, P. L.; Fulton, M. H.; Scott, I. G.; Decho, A. W.; Kashiwada, S. Transfer of gold nanoparticles from the water column to the estuarine food web. Nature Nanotechnol. 2009, 4, 441-444.

(4) Allen, B. L.; Kichambare, P. D.; Gou, P.; Vlasova, I. I.; Kapralov, A. A.; Konduru, N.; Kagan, V. E.; Star, A. Biodegradation of singlewalled carbon nanotubes through enzymatic catalysis. Nano Lett 2008, 8, 3899-3903.

(5) Kirschling, T. L.; Golas, P. L.; Unrine, J. M.; Matyjaszewski, K.; Gregory, K. B.; Lowry, G. V.; Tilton, R. D. Microbial bioavailability of covalently bound polymer coatings on model engineered nanomaterials. Environ. Sci. Technol. 2011, 45, 5253-5259.

(6) Auffan, M.; Pedeutour, M.; Rose, J.; Masion, A.; Ziarelli, F.; Borschneck, D.; Chaneac, C.; Botta, C.; Chaurand, P.; Labille, J.; Bottero, J. Y. Structural degradation at the surface of a TiO2-based nanomaterial used in cosmetics. Environ. Sci. Technol. 2010, 44, 26892694.

(7) Cheng, Y. W.; Yin, L. Y.; Lin, S. H.; Wiesner, M.; Bernhardt, E.; Liu, J. Toxicity reduction of polymer-stabilized silver nanoparticles by sunlight. I. Phvs. Chem. C 2011, 115, 4425-4432.

(8) Hou, W. C.; Jafvert, C. T. Photochemistry of aqueous C(60) clusters: Evidence of ${ }^{1} \mathrm{O}_{2}$ formation and its role in mediating $\mathrm{C}(60)$ phototransformation. Environ. Sci. Technol. 2009, 43, 5257-5262.

(9) Hwang, Y. S.; Li, Q. L. Characterizing photochemical transformation of aqueous $\mathrm{nC}_{60}$ under environmentally relevant conditions. Environ. Sci. Technol. 2010, 44, 3008-3013.

(10) Labille, J.; Feng, J. H.; Botta, C.; Borschneck, D.; Sammut, M.; Cabie, M.; Auffan, M.; Rose, J.; Bottero, J. Y. Aging of $\mathrm{TiO}_{2}$ nanocomposites used in sunscreen. Dispersion and fate of the degradation products in aqueous environment. Environ. Pollut. 2010, $158,3482-3489$.

(11) Metz, K. M.; Mangham, A. N.; Bierman, M. J.; Jin, S.; Hamers, R. J.; Pedersen, J. A. Engineered nanomaterial transformation under oxidative environmental conditions: Development of an in vitro biomimetic assay. Environ. Sci. Technol. 2009, 43, 1598-1604.

(12) Bian, S. W.; Mudunkotuwa, I. A.; Rupasinghe, T.; Grassian, V. $\mathrm{H}$. Aggregation and dissolution of $4 \mathrm{~nm} \mathrm{ZnO}$ nanoparticles in aqueous environments: Influence of $\mathrm{pH}$, ionic strength, size, and adsorption of humic acid. Lanomuir 2011, 27, 6059-6068.

(13) Li, X. A.; Lenhart, J. J.; Walker, H. W. Dissolution-accompanied aggregation kinetics of silver nanoparticles. Langmuir 2010, 26, 16690-16698

(14) Ma, R.; Levard, C.; Marinakos, S. M.; Cheng, Y.; Liu, J.; Michel, F. M.; Brown, J., G. E.; Lowry, G. V. Size-controlled dissolution of organic-coated silver nanoparticles. Environ. Sci. Technol. 2012, in press.

(15) Slowey, A. J. Rate of formation and dissolution of mercury sulfide nanoparticles: The dual role of natural organic matter. Geochim. Cosmochim. Acta 2010, 74, 4693-4708.

(16) Gottschalk, F.; Sonderer, T.; Scholz, R. W.; Nowack, B. Modeled environmental concentrations of engineered nanomaterials ( $\mathrm{TiO} 2, \mathrm{ZnO}, \mathrm{Ag}, \mathrm{CNT}$, fullerenes) for different regions. Environ. Sci. Technol. 2009, 43, 9216-9222.

(17) Kaegi, R.; Voegelin, A.; Sinnet, B.; Zuleeg, S.; Hagendorfer, H.; Burkhardt, M.; Siegrist, H. Behavior of metallic silver nanoparticles in a pilot wastewater treatment plant. Environ. Sci. Technol. 2011, 45, 3902-3908.

(18) Kim, B.; Park, C. S.; Murayama, M.; Hochella, M. F. Discovery and characterization of silver sulfide nanoparticles in final sewage sludge products. Environ. Sci. Technol. 2010, 44, 7509-7514.

(19) Hotze, E. M.; Phenrat, T.; Lowry, G. V. Nanoparticle aggregation: Challenges to understanding transport and reactivity in the environment. I. Environ. Qual. 2010, 39, 1909-1924.

(20) Heathwaite, L.; Haygarth, P.; Matthews, R.; Preedy, N.; Butler, P. Evaluating colloidal phosphorus delivery to surface waters from diffuse agricultural sources. I. Environ. Oual 2005, 34, 287-298.
(21) Kaplan, D. I.; Bertsch, P. M.; Adriano, D. C. Facilitated transport of contaminant metals through an acidified aquifer. Ground water 1995, 33, 708-717.

(22) Huynh, K. A.; Chen, K. L. Aggregation kinetics of citrate and polyvinylpyrrolidone coated silver nanoparticles in monovalent and divalent electrolyte solutions. Environ. Sci. Technol. 2011, 45, 55645571.

(23) Song, J. E.; Phenrat, T.; Marinakos, S.; Xiao, Y.; Liu, J.; Wiesner, M. R.; Tilton, R. D.; Lowry, G. V. Hydrophobic interactions increase attachment of gum arabic-and pvp-coated ag nanoparticles to hydrophobic surfaces. Environ. Sci. Technol. 2011, 45, 5988-5995.

(24) Stebounova, L. V.; Guio, E.; Grassian, V. H. Silver nanoparticles in simulated biological media: A study of aggregation, sedimentation, and dissolution. I. Nanopart. Res. 2011, 13, 233-244.

(25) Tiraferri, A.; Sethi, R. Enhanced transport of zerovalent iron nanoparticles in saturated porous media by guar gum. I. Nanopart. Res. 2009, 11, 635-645.

(26) Phenrat, T.; Song, J. E.; Cisneros, C. M.; Schoenfelder, D. P.; Tilton, R. D.; Lowry, G. V. Estimating attachment of nano-and submicrometer-particles coated with organic macromolecules in porous media: Development of an empirical model. Environ. Sci. Technol. 2010, 44, 4531-4538.

(27) Sirk, K. M.; Saleh, N. B.; Phenrat, T.; Kim, H. J.; Dufour, B.; Ok, J.; Golas, P. L.; Matyjaszewski, K.; Lowry, G. V.; Tilton, R. D. Effect of adsorbed polyelectrolytes on nanoscale zero valent iron particle attachment to soil surface models. Environ. Sci. Technol. 2009, 43, $3803-3808$.

(28) Saleh, N.; Kim, H. J.; Phenrat, T.; Matyjaszewski, K.; Tilton, R. D.; Lowry, G. V. Ionic strength and composition affect the mobility of surface-modified $\mathrm{Fe}(0)$ nanoparticles in water-saturated sand columns. Environ. Sci. Technol. 2008, 42, 3349-3355.

(29) Liu, J. Y.; Hurt, R. H. Ion release kinetics and particle persistence in aqueous nano-silver colloids. Environ. Sci. Technol. 2010, 44, 2169-2175.

(30) Liu, J. Y.; Sonshine, D. A.; Shervani, S.; Hurt, R. H. Controlled release of biologically active silver from nanosilver surfaces. ACS Nano 2010, 4, 6903-6913.

(31) Levard, C.; Reinsch, B. C.; Michel, F. M.; Oumahi, C.; Lowry, G. V.; Brown, G. E., Jr Sulfidation processes of pvp-coated silver nanoparticles in aqueous solution: Impact on dissolution rate. Environ. Sci. Technol. 2011, 45, 5260-5266.

(32) Liu, J. Y.; Pennell, K. G.; Hurt, R. H. Kinetics and mechanisms of nanosilver oxysulfidation. Environ. Sci. Technol. 2011, 45, 73457353.

(33) Choi, O.; Clevenger, T. E.; Deng, B.; Surampalli, R. Y.; Ross, L., $\mathrm{Jr} ; \mathrm{Hu}, \mathrm{Z}$. Role of sulfide and ligand strength in controlling nanosilver toxicity. Water Res. 2009, 43, 1879-1886.

(34) Choi, O.; Deng, K. K.; Kim, N. J.; Ross, L.; Surampalli, R. Y.; $\mathrm{Hu}, \mathrm{Z}$. Q. The inhibitory effects of silver nanoparticles, silver ions, and silver chloride colloids on microbial growth. Water Res. 2008, 42, 3066-3074.

(35) Reinsch, B. C.; Levard, C.; Li, Z.; Ma, R.; Wise, A.; Gregory, K. B.; Brown, G. E., Jr.; Lowry, G. V. Sulfidation decreases silver nanoparticle growth inhibition effects for Escherichia coli. Environ. Sci. Technol. 2012, DOI: DOI: 10.1021/es203732x.

(36) Odum, E. P. The mesocosm. Bioscience 1984, 34, 558-562.

(37) Richardson, C. J., The Everglades Experiments: Lessons for Ecosvstem Restoration; Springer Verlag, 2008; Vol. 201.

(38) Fabrega, J.; Luoma, S. N.; Tyler, C. R.; Galloway, T. S.; Lead, J. R. Silver nanoparticles: Behaviour and effects in the aquatic environment. Environ. Internat. 2010, 37, 517-531.

(39) Kim, J.; Kim, S.; Lee, S. Differentiation of the toxicities of silver nanoparticles and silver ions to the japanese medaka (Oryzias latipes) and the cladoceran daphnia magna. Nanotoxicology 2011, 5, 208-214.

(40) Kumar, N.; Shah, V.; Walker, V. K. Perturbation of an arctic soil microbial community by metal nanoparticles. I. Hazard. Mat. 2011, 190, 816-822.

(41) Shoults-Wilson, W.; Reinsch, B. C.; Tsyusko, O. V.; Bertsch, P. M.; Lowry, G. V.; Unrine, J. M. Role of particle size and soil type in 
toxicity of silver nanoparticles to earthworms. Soil Sci. Soc. Amer. I. 2011, 75, 365-377.

(42) Shoults-Wilson, W. A.; Reinsch, B. C.; Tsyusko, O. V.; Bertsch, P. M.; Lowry, G. V.; Unrine, J. M. Effect of silver nanoparticle surface coating on bioaccumulation and reproductive toxicity in earthworms (Eisenia fetida). Nanotoxicology 2011, 5, 432-444.

(43) National Research Council. National hydric soils list. 2009. (cited 2009 March 17); http://soils.usda.gov/use/hydric/.

(44) Bryant, L. D.; Hsu-Kim, H.; Gantzer, P. A.; Little, J. C. Solving the problem at the source: Controlling $\mathrm{mn}$ release at the sedimentwater interface via hypolimnetic oxygenation. Water Res. 2011, 45, 6382-6392.

(45) Allen, H. E.; Fu, G.; Deng, B. Analysis of acid volatile sulfide (AVS) and simultaneously extracted metals (sem) for the estimation of potential toxicity in aquatic sediments. Environ. Toxicol. Chem. 1993, 12, 1441-1453.

(46) Cline, J. D. Spectrophotometric determination of hydrogen sulfide in naturaters. Limnol. Oceanogr. 1969, 14, 454-458.

(47) Kim, C. S.; Rytuba, J. J. Characterization and speciation of mercury-bearing mine wastes using x-ray absorption spectroscopy. $\underline{S_{c i}}$. Total Environ. 2000, 261, 157-168.

(48) Reinsch, B. C.; Forsberg, B.; Penn, R. L.; Kim, C. S.; Lowry, G. V. Chemical transformations during aging of zerovalent iron nanoparticles in the presence of common groundwater dissolved constituents. Environ. Sci. Technol. 2010, 44, 3455-3461.

(49) Bowles, K. C.; Bell, R. A.; Ernste, M. J.; Kramer, J. R.; Manolopoulos, H.; Ogden, N. Synthesis and characterization of metal sulfide clusters for toxicological studies. Environ. Toxicol. Chem. 2002, 21, 693-699.

(50) Chinnapongse, S. L.; MacCuspie, R. I.; Hackley, V. A. Persistence of singly dispersed silver nanoparticles in natural freshwaters, synthetic seawater, and simulated estuarine waters. $\underline{S c i}$. Total Environ. 2011, 409, 2443-2450.

(51) Hyung, H.; Fortner, J. D.; Hughes, J. B.; Kim, J. H. Natural organic matter stabilizes carbon nanotubes in the aqueous phase. Environ. Sci. Technol. 2007, 41, 179-184.

(52) Stankus, D. P.; Lohse, S. E.; Hutchison, J. E.; Nason, J. A. Interactions between natural organic matter and gold nanoparticles stabilized with different organic capping agents. Environ. Sci. Technol. 2011, 45, 3238-3244.

(53) Luther, G. W.; Reimers, C. E.; Nuzzio, D. B.; Lovalvo, D. In situ deployment of voltammetric, potentiometric. And amperometric microelectrodes from a rov to determine dissolved $\mathrm{O}_{2}, \mathrm{Mn}$, $\mathrm{FeS}(-2)$, and $\mathrm{pH}$ in porewaters. Environ. Sci. Technol. 1999, 33, $4352-4356$.

(54) Andren, A. W. Bober, T. W., Silver in the Environment: Transport, Fate, and Effects; Society of Environmental Toxicology and Chemistry: Pensacola, Fl, 2002.

(55) Fortin, C.; Campbell, P. G. C. Thiosulfate enhances silver uptake by a green alga: Role of anion transporters in metal uptake. Environ. Sci. Technol. 2001, 35, 2214-2218.

(56) Di Toro, D. M., Mahony, J. D., Carbonaro, R. F., Love, J. H., Morrissey, J. C. The bioavailability of silver in sediment. In 5th International Conference Proceedings: Transport, Fate and Effects of Silver in the Environment; Sea Grant Institute. University of Wisconsin: Madison WI, 1997. 